\title{
Implications of nestin in breast cancer pathogenesis (Review)
}

\author{
ALEKSANDRA NOWAK $^{1}$ and PIOTR DZIEGIEL ${ }^{1,2}$ \\ ${ }^{1}$ Department of Human Morphology and Embryology, Division of Histology and Embryology, Wroclaw Medical University, \\ 50-368 Wroclaw; ${ }^{2}$ Department of Physiotherapy, University School of Physical Education, 51-612 Wroclaw, Poland
}

Received March 15, 2018; Accepted May 14, 2018

DOI: 10.3892/ijo.2018.4441

\begin{abstract}
The aim of the present review was to summarize the current knowledge of the involvement of nestin in breast cancer (BC) pathogenesis. Nestin is a member of the class VI family of intermediate filament proteins, originally identified as a marker of neural stem cells and subsequently demonstrated to be expressed in $\mathrm{BC}$ and other cancer types. In normal breast tissue, nestin is expressed in the basal/myoepithelial cells of the mammary gland. In BC, nestin identifies basal-like tumours and predicts aggressive behaviour and poor prognosis. Nestin expression has also been detected in BC stem cells and newlyformed tumour vessels, being a factor in promoting invasion and metastasis. The present review provides an up-to-date overview of the involvement of nestin in processes facilitating $\mathrm{BC}$ pathogenesis and progression.
\end{abstract}

\section{Contents}

1. Introduction

2. Nestin protein structure

3. Role of nestin in cell cycle regulation and survival

4. Nestin expression in the normal breast and in $\mathrm{BC}$

5. Nestin as a marker of basal-like BC

6. Nestin as a marker of $\mathrm{BC}$ stem cells

7. Role of nestin in $\mathrm{BC}$ angiogenesis

8. Nestin in BC-targeted therapy

9. Conclusion

\section{Introduction}

According to Globocan, breast cancer (BC) is the most common cancer in women, with an estimated 1.67 million new cancer

Correspondence to: Miss Aleksandra Nowak, Department of Human Morphology and Embryology, Division of Histology and Embryology, Wroclaw Medical University, Chalubinskiego 6a, 50-368 Wroclaw, Poland

E-mail: alexandra.m.nowak@gmail.com

Key words: nestin, breast cancer, basal-like breast cancer, cancer stem cells, angiogenesis cases being diagnosed in 2012 (1). Globocan estimates that BC is the 5th most common cause of mortality among the overall cancer mortalities (522,000 mortalities) and is considered the principal cause of cancer-associated mortality in women in less developed regions (324,000 mortalities). The recent decline in mortality rates of $\mathrm{BC}$ in developed regions has been associated with more effective screening programmes, improved chemotherapeutic options and targeted therapy (2-4).

For a number of years, pathologists have recognized the biological heterogeneity among BCs. BCs are diversified into a few biologically distinct subtypes with specific pathological features and different clinical behaviours (5-7). Initially, breast tumours were classified according to histological type, grade and the expression of steroid receptors $(8,9)$. However, pioneering gene expression profile studies demonstrated that the morphological heterogeneity of $\mathrm{BC}$ is also reflected at the gene expression level (10-13). These studies allowed for the classification of BCs into five intrinsic molecular subtypes: Luminal A and B; normal breast-like; with overexpression of erb-b2 receptor tyrosine kinase 2/human epidermal growth factor receptor 2 (HER2); and basal-like carcinomas (10-13). However, gene expression profiling-based techniques are not very common in daily clinical practice due to their relatively high cost. Routine histopathological subclassification of $\mathrm{BC}$ is primarily accomplished by immunohistochemical (IHC) detection of oestrogen receptor (ER), progesterone receptor (PR), HER2 and marker of proliferation Ki-67 (Ki-67) (14). Different expression patterns of these biomarkers provide a simple clinical classification system for BCs and allow for the determination of therapeutic approaches. According to The St. Gallen surrogate classification, BCs may be classified by IHC into four subtypes: Luminal A $\left(\mathrm{ER}^{+}, \mathrm{PR}^{+}, \mathrm{HER} 2\right.$ and low $\mathrm{Ki}-67$ index); luminal $\mathrm{B}\left(\mathrm{ER}^{+}, \mathrm{PR}^{+}\right.$and HER2 ${ }^{+}$or high $\mathrm{Ki}-67$ index); HER2-positive (ER- $\mathrm{PR}^{-}, \mathrm{HER} 2^{+}$); and triple negative breast cancer (TNBC; ER', PR', HER2') (15). TNBC is one of the most challenging subtypes among $\mathrm{BC}$ due to the lack of targeted therapies and its highly aggressive clinical behaviour (16-18). TNBCs may also be clustered into at least two distinct molecular classes according to their different behaviours: The basal phenotype and non-basal-like TNBCs (5). This distinction within TNBCs is important from a clinical perspective due to the different responses to chemotherapeutic treatment of each subtype (19). The basal-like subtype originates in the myoepithelial/basal cells that line the outer layer of mammary ducts, and is characterized by a high proliferation rate, aggressive pathological features and an extremely 
poor clinical outcome (20-22). Although the identification of basal-like cancer is optimally performed by gene expression profiling, attempts have been made to establish a reliable IHC panel for its identification. According to Nielsen et al (23), basal-like BCs are characterized as ER, PR and HER2negative tumours with overexpression of basal cytokeratins $5 / 6$ or epidermal growth factor receptor (EGFR). This IHC panel, termed 'Core Basal', has been validated and widely applied for basal-like subtype identification $(23,24)$. However, to depict the heterogeneity of $\mathrm{BCs}$, the evidence from a number of studies demonstrates that certain basal-like by gene expression tumours weakly express steroid receptors, which results in the misclassification of the majority of them as luminal tumours by IHC (25-30). According to the current standards, the luminal subtype is reported when $<1 \%$ of the tumour cells express ER by IHC. Tumours weakly expressing ER comprise a relatively rare subgroup characterized by positive nuclear staining of $1-10 \%$ cells $(29,31)$, with an incidence ranging between 1 and $6.7 \%(32,33)$. A number of studies demonstrated that approximately one-half of weakly ER-positive cases exhibit different gene expression patterns compared with luminal tumours, overlapping with the basal-like gene profile and predicting poor prognosis $(29,31)$. Currently, patients in this subgroup are scheduled to receive endocrine therapy, which in that case may not only be ineffective, but may also expose them to unnecessary side effects, thus limiting their opportunities to benefit from chemotherapy-based treatments. To date, a single panel of IHC markers for the specific identification of basallike tumours remains to be validated. However, considering recent findings, nestin, a marker of stem cells, appears to be a sensitive IHC marker for basal-like subtype identification, regardless of ER status $(34,35)$.

Nestin (a neural stem cell protein) is a member of the class VI family of intermediate filament (IF) proteins, originally identified as a marker of neural progenitors and subsequently observed to be expressed in a wide range of other cell types (36-38). Nestin was initially identified as a protein expressed in the developing central nervous system (CNS) in neuroepithelial stem cells that give rise to neurons and glia $(39,40)$. The expression of nestin in adults is uncommon; it is restricted to very specific cell types and may be induced only during particular processes i.e., development and regeneration (41-44). In tissues, nestin-positive cells are limited to defined locations where they may function as quiescent reserve cells, which are capable of proliferation, differentiation and migration when reactivated (37). During cell differentiation, nestin expression is subsequently downregulated and replaced by tissue-specific IF proteins (45). Except for the expression in the CNS, nestin has additionally been identified in stem and progenitor cells of the muscles (46-48), teeth (49), testes (50), pancreas (51), intestines (52), bone marrow (53), hair follicles $(54)$, endothelium $(55,56)$ and other tissues. Nestin expression in tumour cells was initially reported in neuroectodermal tumours of the CNS $(57,58)$. Further studies on nestin expression demonstrated that it is also present in epithelial cancer, including breast (59), prostate (60), pancreatic (61), lung (62), ovarian (63) and other cancer types. Additionally, in a number of tumours the expression of nestin is considered a factor indicating poor prognosis (64-67). Furthermore, nestin expression in tumours is not limited to cancer cells, and is also present in newly-forming tumour vessels and cancer stem cells (CSCs) $(56,68)$.

The present review discusses the role of nestin as a significant agent involved in the mechanisms underlying $\mathrm{BC}$ progression. Being involved in proliferation, angiogenesis and self-renewal, nestin may be hypothesized to be an important factor in $\mathrm{BC}$ pathogenesis.

\section{Nestin protein structure}

The human nestin protein consists of 1,621 amino acids with a predicted molecular weight of $177.4 \mathrm{kDa}$. Nestin was classified as new type (type VI) of IF as it did not fall clearly into any of the previously described types (69). As in all IFs, nestin has a highly conserved $\alpha$-helical core domain of 300-330 amino acids flanked by $\mathrm{N}$ - and $\mathrm{C}$-terminal domains (36). However, nestin has two intrinsic features that determine its two unique properties. A short $\mathrm{N}$-terminal head domain prevents nestin self-assembly and, as a result, nestin co-polymerizes forming heterodimers with other IFs, most favourably with vimentin (70,71). Additionally, nestin has an unconventionally long C-tail domain that protrudes from the filament structure, being accessible to post-translational modifications and protein interactions (36).

\section{Role of nestin in cell cycle regulation and survival}

Although the exact mechanisms of action of nestin in BC development remain unknown, there have been certain studies elucidating its role in the cell cycle, proliferation and survival. Accumulating data suggests that IF protein phosphorylation markedly alters the structure/dynamics of IFs in cells $(72,73)$. Nestin has multiple phosphorylation sites and has been demonstrated to be phosphorylated by kinases involved in cell cycle regulation, for example cyclin-dependent kinase 1 [additionally termed cell division control protein 2 homolog (cdc2)] and cyclin-dependent kinase 5 (Cdk5) $(74,75)$. In rat cells, cdc2 kinase is involved in the phosphorylation of nestin in the highly conserved rod domain, regulating its intracellular organization during mitosis (4). Recently, it was reported that nestin phosphorylation directly affects the proliferation of cancer cells (76). Nestin also modulates Cdk5 activity, a kinase that has recently been demonstrated to be involved in tumorigenesis, with functions ranging from cell proliferation to invasion and angiogenesis (74,77-79). In BC, the overexpression of the Cdk5/p35 complex is associated with markers of poor prognosis, $\mathrm{TNBC}, \mathrm{Her} 2^{+}$expression and high grade of malignancy (79). In normal cells, nestin serves as a potent survival determinant acting via cytoplasmic sequestration of the $\mathrm{Cdk} 5 / \mathrm{p} 35$ complex, which protects cells from oxidative stress-induced cell death (80). In the nucleus, Cdk5 forms a complex with $\mathrm{p} 25$, which is generated as a product of the proteolytic cleavage of $\mathrm{p} 35$. Nestin, acting as a protein scaffold, stabilizes p35 and prevents the translocation of Cdk5/p25 to the nucleus, which is a required step for the induction of cell death (80). Nestin was also reported to drive protein hedgehog (Hh)-dependent tumorigenesis by binding to transcriptional activator Gli3, a zinc finger transcription factor that negatively regulates $\mathrm{Hh}$ signalling (81). The Hh pathway has been recognized as one of the key signalling pathways involved in 
the pathogenesis of TNBC (82). Lines of evidence suggest that nestin is directly involved in the mechanisms underlying tumour growth and progression. However, further studies are required to clarify its oncogenic role in $\mathrm{BC}$.

\section{Nestin expression in the normal breast and in BC}

The first evidence of nestin expression in human BC tissues was demonstrated by Li et al (59). In that study, nestin expression was detected in the regenerative compartment of the normal human mammary gland in addition to BC tumour cells. The study demonstrated that in mammary ducts and lobules, nestin was expressed in the subluminal compartment in two morphologically distinct cell types: In columnar basal cells expressing tumour protein p63 and normal cytokeratin-14; and in filamentous myoepithelial cells expressing desmin (59). Additionally, the study demonstrated that during murine pregnancy, nestin coordinately colocalized with p63 in columnar basal cells and was involved in the regenerative cycle of the mammary gland. On the other hand, nestin expression in myoepithelial cells appeared to be stable throughout the course of pregnancy. Nestin-expressing cells have also been isolated from human breast milk, which suggests that it may be a novel source of putative stem cells (83-85). A further study indicated that these nestin-expressing cells were able to differentiate into neural stem cells and neurons (86). The role of nestin in the process of self-renewal in BC has been confirmed by additional studies (87-89).

\section{Nestin as a marker of basal-like BC}

The study by Li et al (59) demonstrated that nestin expression is increased among BRCA1-associated tumours and suggested that nestin may be a selective marker of basal-like BCs. However, the study had important limitations. Specifically, the classification of basal-like tumours was not based on the results from gene expression profiling, and rather on the IHC expression patterns of ER, PR and HER2. Furthermore, the number of analysed samples was relatively low (16 cases classified as TNBCs, 16 cases as luminal and 16 cases as HER $2^{+}$), thus the results require verification in further large population-based studies. However, the high number of nestinexpressing cases (14/16) among the TNBCs and the lack of expression reported in luminal (0/16) and HER2-positive $(0 / 16)$ tumours suggested that nestin may be an important marker of BC differentiation. Further studies confirmed the clinical implications of nestin expression in TNBC and basallike tumours $(34,55,90-97)$. Parry et al (90), in an IHC study of 245 human invasive BC cases, demonstrated that nestin expression in tumour cells was predominantly observed in basal-like tumours, as defined by the IHC panel proposed by Nielsen et al (23). Notably, the researchers reported that $2.6 \%$ of luminal cancer cases also expressed high levels of nestin and a few other basal markers. The study also demonstrated that nestin expression was positively correlated with grade III tumours, a high Ki-67 proliferation index and nuclear expression of p53 (90). Although nestin expression was associated with poor survival rates among patients with nodal metastasis, nestin was not an independent prognostic factor in multivariate analysis (90). Similar results were obtained by Liu et al (91), who demonstrated an association of nestin with the TN phenotype, lymph node metastasis and p53 expression. In that study, it was also reported that nestin expression was a poor prognostic factor among patients with lymph node metastasis; however, in general, nestin was not an independent prognostic factor for BC. Finally, Liu et al (91) demonstrated that an increased expression level of nestin was noted in invasive tumours when compared with in situ tumours. Another study conducted on locally advanced T4 tumours demonstrated that nestin was associated with the TN phenotype, poor prognosis and inflammatory breast cancer (IBC) (92). IBC is a rare and very aggressive subtype of $\mathrm{BC}$ characterized by rapid progression, poor prognosis and enhanced lymphovascular invasion $(98,99)$. A total of $\sim 80 \%$ of highly aggressive inflammatory tumours were reported to express nestin (92). Nestin-expressing cells were also detected in the lymphovascular emboli of IBC, which may suggest that these clusters of cells expressing nestin and other stemness markers may be CSCs (100). Notably, the study by Piras et al (92) reported that nestin expression was present in cancer cells and also in peritumoural stromal cells with a fibroblastlike morphology, although the analysis did not reveal any association with TNBC or IBC. Rogelsperger et al (101) reported that nestin co-localized with the melatonin receptor (MT1) in tumour cells among BC patients with higher disease stages (II and III) and with a higher risk of relapse.

Although gene expression profiling is the gold standard facilitating accurate classification of basal-like tumours, its application is expensive and impractical in everyday practice. Thus, surrogate IHC panels are the first-choice strategy in basal-like subtype identification, even with their lower sensitivity and specificity. In order to identify the best individual IHC marker, Won et al (93) tested 46 biomarkers associated with the basal-like subtype, against a gene expression profile gold standard. On the basis of the highest odds ratio, nestin was the best positive biomarker identifying the basal-like intrinsic subtype among all of the investigated biomarkers. Furthermore, a combined IHC panel composed of nestin positivity and/or inositol polyphosphate-4-phosphatase negativity (nestin ${ }^{+} /$INPP4B $^{-}$) had a better sensitivity and specificity compared with any other proposed IHC panel for basal-like subtype identification (93). In their further study, application of the nestin ${ }^{+} /$INPP4B $^{-}$panel enabled the classification of the majority of weakly ER-positive cases as basal-like, in accordance with the results obtained by the gold standard assay (35). To validate these findings, the researchers evaluated the prognostic value of nestin as a single positive biomarker of basal-like cancer in a large cohort of 3,641 earlystage invasive BC cases (34). Currently, all established IHC panels for basal-like cancer identification require ER negativity $(23,102,103)$, therefore any new IHC marker that may be interpreted independently of ER may be a valuable diagnostic tool. Therefore, nestin, as an abundantly and stably expressed cytoskeletal protein, may be helpful for classifying clinically problematic cases with weak expression of ER. In a cohort comprising 2,323 $\mathrm{ER}^{+}$cases as defined by IHC, nestin ${ }^{+}$ expression was noted in 5\% of $\mathrm{ER}^{+}$tumours (120 patients) and was an independent poor prognostic factor for patients within this subgroup (34). The same trend for nestin was observed in $\mathrm{ER}^{+}$patients receiving endocrine therapy only; however, due 
to the small number of cases, the results were not statistically significant. To support the findings that nestin expression may reliably identify basal-like tumours within the $\mathrm{ER}^{+}$subgroup, Asleh et al (34) analysed 672 nestin $^{+}$cases against a gene expression profiling assay. As in their previous study (35), nestin expression was strongly associated with the intrinsic basal-like subtype, established by the gold standard assay. These results contributed to the improved understanding of the issue of nestin ${ }^{+} \mathrm{ER}^{+}$cases reported by Parry et al (90), which according to the standards were classified as luminal by IHC. In the study by Asleh et al (34), nestin expression was observed in $371(10 \%)$ out of all the investigated cases and was associated with high-risk clinicopathological factors (younger age, higher grade and high proliferation index). In contrast to Parry et al (90) and Liu et al (91), the analysis of long-term survival data demonstrated that nestin positivity was an independent poor prognostic factor in BC. However, the previous studies examining the prognostic value of nestin have certain limitations which may clarify such an inconsistency in the results. For instance, in the studies by Liu et al (91) and Parry et al (90), the number of nestin ${ }^{+}$cases included in the analyses was relatively low, comprising 24 and 20 cases respectively. Additionally, the study by Asleh et al (34) analysed early-stage BC cases of which $42 \%$ of the patients had not received any systemic treatment, whereas all the patients studied by Parry et al (90) received anthracycline-based adjuvant chemotherapy, which may have influenced the survival rates. Recent data from a second large cohort by Kruger et al (96) also support the finding that nestin is associated with aggressive tumour characteristics (size, grade, proliferation, $\mathrm{p} 53$ expression and blood vessel invasion) and the basal-like BC phenotype. Notably, in contrast to Liu et al (91), Kruger et al noted nestin expression more frequently in patients with negative lymph node status. In fact, it had been proposed in previous studies that basal-like BCs preferentially spread haematogenously, giving rise to metastatic deposits in the brain and lungs (104). Similar to Asleh et al (34), the researchers confirmed the predictive value of nestin as an independent prognostic factor associated with poor prognosis (96). Additionally, the study by Kruger et al (96) demonstrated that nestin protein, in addition to nestin mRNA expression, was associated with DNA repair associated (BRCA1) germline mutations, particularly among young women. Nestin appeared to be a stronger predictor of BRCA1 germline mutation compared with any other investigated core marker [including cytokeratin 5 (CK-5), EGFR, P-cadherin and intrinsic basal-like subtype]. Moreover, nestin mRNA expression levels and signature scores varied among TNBC subgroups, as described by Lehmann et al (105), being highest in the basal-like 1, mesenchymal and mesenchymal stem-like subgroups (96). Recently, the potential of treatment of BRCA-associated cancer with poly-(ADP ribose) polymerase inhibitors (PARPi) has been recognised, with a number of molecules being under clinical trials (106). As a strong predictor of BRCA1 mutation, nestin may be a valuable tool for identifying patients eligible for PARPi targeted therapy, although the validity of its predictive value requires further study.

An additional study of 2,930 cases investigated whether the protein expression pattern in primary tumours may influence the first site of distant metastases (107). It was revealed that the expression of nestin, prominin-1 (CD133) or CK-5 in the primary tumour were significantly associated with brain metastases as the first site of distant recurrence. Since nestin and CD133 are proteins expressed by neural stem cells, that previous study appeared to be in accordance with Paget's 'seed and soil' theory, postulating that metastasis depends on the interaction between cancer cells and the specific organ microenvironment (108). Hypothetically, BC cells expressing neural stem cells markers may also share the same features and may thus be particularly well adapted to the brain microenvironment to initiate brain metastases. However, the biological mechanisms associated with these proteins and $\mathrm{BC}$ brain metastases remain unknown. According to prognostic prediction, the 1-year survival rate of patients with $\mathrm{BC}$ brain metastases is $<20 \%$ (109). Meisen et al (110) proposed nestintargeted therapy for breast cancer metastases in two murine models. Targeting BC brain metastases with an oncolytic virus programmed to kill nestin-expressing cells, and to deliver the extracellular domain of brain angiogenesis inhibitor 1, significantly enhanced the survival of mice with established metastatic BC brain tumours. Meisen et al (110) also investigated the cytotoxic effect of the same nestin-targeting virus on four human $\mathrm{BC}$ cell lines corresponding to the different biological types of BC. According to Neve et al (111), BC cell lines may be clustered into three major subsets (luminal, basal A and basal B), which reflect the molecular subtypes of primary tumours. Using the publicly accessible 'Neve breast cancer dataset', Meisen et al (110) compared nestin gene expression in $50 \mathrm{BC}$ cell lines included in the analysis. Although nestin mRNA was detected in all investigated cell lines, increased expression levels were observed in the basal A cluster, which matched the Perou basal-like signature of primary tumours $(10,11)$. The in vitro cell viability assay on the cell lines representing the luminal (MCF7 and SKBR3), Basal A (MDA-MB-468) and Basal B (MDA-MB-231) clusters indicated that the same oncolytic virus exerted its cytotoxic effect on all the investigated cell lines (110). Predictably, the most significant cytotoxicity was observed in the MDA-MB436 cells expressing the highest levels of nestin.

\section{Nestin as a marker of $\mathrm{BC}$ stem cells}

CSCs are defined as a small subpopulation of undifferentiated tumour cells that are characterized by their capacity for self-renewal and ability to differentiate into multiple tumour cell types $(68,112,113)$. The ability of CSCs to reproduce a continuously growing tumour, described as 'tumorigenicity', is responsible for therapeutic resistance and metastasis $(68,114)$. The first study demonstrating the involvement of nestin in the biology of CSCs analysed nestin expression in CSCs isolated from different types of human CNS tumours $(115,116)$. Further studies have confirmed the utility of nestin as a potent marker of tumour cells exhibiting a stem-like phenotype. In BCs, cells with a stem-like phenotype may be identified based on the expression patterns of cell surface markers, and are described as CD44 antigen (CD44) ${ }^{+}$and signal transducer CD24 $(\mathrm{CD} 24)^{- \text {llow }}$ (117). Further studies demonstrated that a high number of $\mathrm{CD} 44^{+} / \mathrm{CD} 24^{- \text {/low }}$ cells may be particularly observed in TN tumours and cell lines, being a predictor of poor prognosis and aggressive behaviour $(118,119)$. Liu et al $(120)$ 
demonstrated that these $\mathrm{CD} 44^{+} / \mathrm{CD} 24^{-/ \text {low }}$ cells, which highly expressed nestin and another relevant stem cell marker [POU domain, class 5, transcription factor 1 (Oct-4)], had a greater ability to form mammospheres in vitro (119). Furthermore, it was demonstrated that nestin and Oct- 4 co-expression was significantly associated with younger age, higher histological grade, lymph node metastasis and TN phenotype. Furthermore, multivariate analysis of survival indicated that the co-expression of these two markers was associated with shorter survival independent of age, lymph node metastasis and $\mathrm{TN}$ phenotype. In IBC, nestin expression was detected in cells forming tumour emboli within lymphatic vessels (100). These nestin ${ }^{+}$cells formed spheroids expressing other CSC markers (including CD $44^{+} / \mathrm{CD} 24^{- \text {llow }}$, aldehyde dehydrogenase cytosolic 1 and CD133) and stemness-associated transcription factors [Oct-4, homeobox protein NANOG (Nanog) and transcription factor (SOX-2)]. Furthermore, it was identified that nestin $^{+}$spheroids were resistant to radiotherapy and chemotherapy and strongly contributed to distant metastasis (121). The study by Apostolou et al (89) confirmed the co-expression of nestin and other stemness markers (including Oct3/4, Nanog and SOX-2) in circulating tumour cells (CTCs) isolated from clinical patients. Notably, their results indicated a marked association between the expression of these markers in CTCs and the stage of the disease. The mechanism underlying the involvement of nestin in the biology of CSCs was described by Zhao et al (88). In that study, the researchers investigated the role of nestin in primary CSCs isolated from BC tumours. First, they studied the behaviour of naturally occurring nestin ${ }^{\text {high }}$ and nestin ${ }^{\text {low }}$ populations of CSCs. Subsequently, the authors examined the behaviour of primary CSCs with genetically modified nestin expression by overexpressing or silencing the $N E S$ gene. Cells with nestin ${ }^{\text {high }}$ and nestin-overexpressing cells had potent tumorigenicity, displayed by rapid mammosphere formation in vitro and the induction of solid tumours in vivo. Silencing of nestin expression induced cell cycle arrest at the $\mathrm{G} 2 / \mathrm{M}$ phase, promoted apoptosis and reduced the expression of epithelial-mesenchymal transition (EMT) markers (including $\mathrm{N}$-cadherin, vimentin and $\alpha$-smooth muscle actin). EMT is a dynamic process that appears to facilitate tumour metastasis by switching the cell phenotype from epithelial to mesenchymal $(122,123)$. Furthermore, nestin silencing significantly upregulated the expression of proteins involved in the inhibition of the $\mathrm{Wnt} / \beta$-catenin pathway, which is crucial for the regulation of the proliferation and tumorigenicity of stem cells (124-127). In addition, the inhibition of the Wnt/ $\beta$-catenin pathway in nestin ${ }^{\text {high }}$ CSCs significantly limited their tumorigenicity.

To date, a number of natural compounds have been investigated to target breast CSCs. The inhibitory effect of Huaier aqueous extract and nitidine chloride (a natural polyphenolic compound isolated from the root of Zanthoxylum nitidum) on CSCs has been tested in BC cell lines $(128,129)$. The two compounds significantly reduced the number of $\mathrm{CD} 44^{+/} \mathrm{CD} 24^{-/ \text {low }}$ cells and decreased the expression of nestin and other pluripotency markers (including Nanog and Oct-4). It was suggested that the inhibition of nestin, Nanog and Oct-4 occurred via the inhibition of the Hh pathway $(128,129)$. The Hh signalling pathway is associated with normal mammary gland development and its activation, either by mutation or aberrant expression of pathway components, leads to BC development (130). A recent study reported that in TNBC, nestin expression may be regulated by the SOX-10 transcription factor, which directly binds to the nestin promoter and enhances its expression (131). SOX-10 is specifically expressed in mammary cells exhibiting the highest levels of stem/progenitor activity, and in breast tumours with stem-like behaviour (132). SOX10 knockdown significantly inhibits nestin expression and decreases the stem-like features of $\mathrm{TNBC}$, in terms of the $\mathrm{CD} 44^{+} / \mathrm{CD} 24^{-/ \text {low }}$ cell ratio and tumour sphere-forming abilities (131). Importantly, the effect of SOX10 knockdown on the properties of CSCs is partly counteracted by enforcing nestin expression.

\section{Role of nestin in $\mathrm{BC}$ angiogenesis}

Angiogenesis is the process of new blood vessel formation, which involves numerous mechanisms mediating the growth and modification of a capillary network $(133,134)$. The process was first described in breast tumours by Folkman (135) and became the basis for further research, demonstrating that sustained angiogenesis is an integral part of the progression of the majority of cancer types (135-137). Studies on nestin expression in human tumours have demonstrated that nestin is expressed in tumour cells and also in tumour vessels $(55,138)$. These observations led to further research examining the role of nestin in the process of angiogenesis in breast and other cancer types.

The first immunohistochemical study on the nestinexpressing microvasculature in BC clinical samples was conducted by Kruger et al (139). The study aimed to evaluate angiogenesis via the assessment of immature (nestin ${ }^{+}$) and proliferating $\left(\mathrm{Ki}-67^{+}\right)$endothelial cells in breast tumour tissue. The study demonstrated that nestin and $\mathrm{Ki}-67$ co-expression in tumour vessels, in addition to nestin ${ }^{+}$microvessel density (nestin ${ }^{+}$MVD), were significantly associated with the basal-like phenotype and a negative ER and PR status. The study also assessed the prognostic value of the vascular proliferation index (VPI), which was calculated as the ratio between the number of nestin ${ }^{+} \mathrm{Ki}-67^{+}$microvessels and the total number of nestin ${ }^{+}$microvessels expressed as a percentage. It was demonstrated that the VPI was increased in invasive ductal carcinoma (IDC) compared with invasive lobular carcinoma (ILC). Furthermore, an increased VPI was significantly associated with a shorter overall survival in univariate and multivariate analyses. However, the prognostic value of nestin ${ }^{+}$MVD was not confirmed in the study (139). The prognostic value of nestin ${ }^{+}$MVD was demonstrated in our recent study (56). It was observed that the number of nestin-expressing microvessels was noticeably increased in invasive tumours compared with pre-invasive lesions. Additionally, a high value of nestin ${ }^{+}$MVD was associated with disease progression, stage, lymph node metastasis, high tumour grade and the TN phenotype. Our study demonstrated that a high value of nestin ${ }^{+}$MVD was an independent factor for poor prognosis in BC. Notably, it was also reported that the number of nestin-expressing vessels was significantly correlated with immature $\mathrm{CD} 34^{+}$, although not with mature platelet endothelial cell adhesion molecule $(\mathrm{CD} 31)^{+}$vessels (56). To confirm these results, nestin expression was analysed in endothelial cell lines isolated from 
A
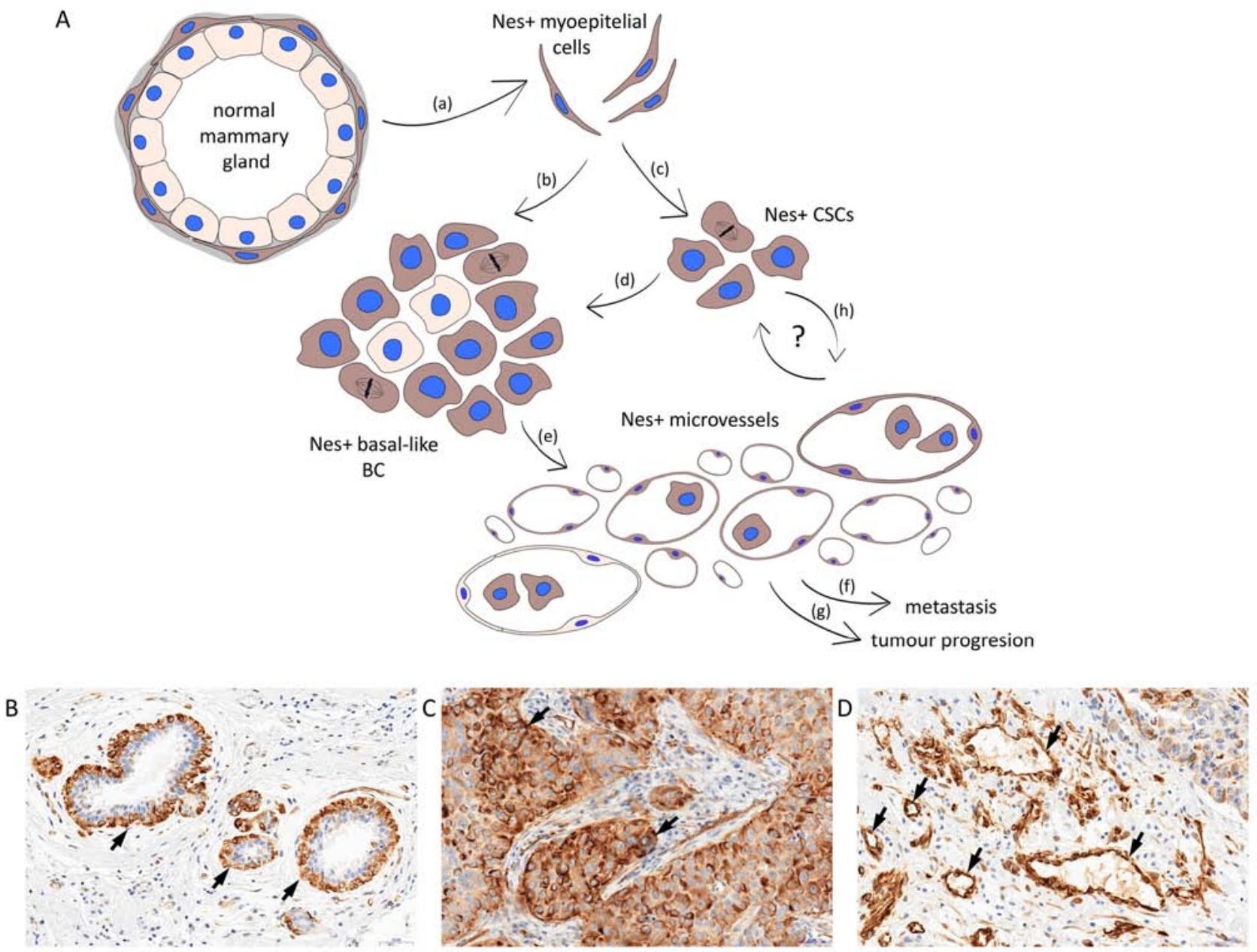

Figure 1. Role of nestin in the pathogenesis of basal-like BC. (A) Nestin expression (brown) is detected in the basal/myoepithelial layer of the normal mammary gland. (a) Nestin ${ }^{+}$myoepithelial cells give rise to (b) nestin ${ }^{+}$basal-like tumours and (c) nestin ${ }^{+}$CSCs that are able to (d) repopulate the tumour. Nestin expression is also observed in newly-formed tumour vessels. The number of nestin-expressing vessels correlates with (e) nestin expression in tumour cells, (f) metastasis and (g) tumour progression. (h) Some evidence indicates that cancer stem cells are also able to differentiate into endothelial cells and/or form vessel-like structures through a process termed vasculogenic mimicry. Immunohistochemically detected nestin expression in the basal/myoepithelial layer of (B) the normal mammary gland, (C) the basal-like BC and (D) the BC associated-vessels. Magnification, x300. Nes, nestin; BC, breast cancer; CSCs, cancer stem cells.

various types of human vessels. Different patterns of nestin expression were noted in the human endothelial cells according to their maturity. It was observed that particularly high nestin expression occurred in an early endothelial progenitor cell line, originating from human umbilical cord blood (140), compared with endothelial cells from dermal microvessels and the umbilical vein (56). Taken together, these results suggested that nestin expression may reflect the progenitor nature of vessels, and that it is primarily limited to undifferentiated and newly forming vessels.

Based on the knowledge that nestin is also detected in pericytes (141), Nakagawa et al (142) evaluated the differences in vascular density (CD31 $\left.1^{+} \mathrm{MVD}\right)$, vascular proliferation (vasohibin $-1^{+} / \mathrm{CD} 31^{+}$ratio) and microvessel maturation (nestin ${ }^{+} /$ vasohibin- $1^{+}$ratio) between IDC and ILC. The maturation of blood vessels may be marked by the presence of pericytes surrounding the microvessels. It has been demonstrated that tumour microvessels are characterized by abnormal pericyte coverage in addition to disturbed interactions between pericytes and endothelial cells, the two of which may contribute to metastatic dissemination (143). Notably, Nakagawa et al (142) reported nestin expression only in pericytes; however, they did not mention the presence of nestin in the endothelium. The study demonstrated that the CD $31^{+} \mathrm{MVD}$ and the vasohibin- $1^{+} /$ $\mathrm{CD} 31^{+}$ratio were significantly higher in ILC compared with IDC. However, nestin immunoreactivity in intratumoural microvessels in ILC was significantly lower. It was suggested that the proliferation of microvessels was enhanced in ILC, although these vessels were less mature compared with those in IDC (142).

In another study, it was demonstrated that nestin expression in $\mathrm{BC}$ cells was positively correlated with the area and number of vessels expressing different endothelial antigens, including nestin, CD31, CD34 and transcription factor SOX-18 (97). Another recent study also confirmed that nestin expression in tumour cells was associated with higher VPI and blood vessel, although not lymphatic vessel, invasion (96). Furthermore, a positive correlation was observed between the area and number of nestin-expressing vessels and vessels expressing the transcription factor SOX-18, which is an important regulator of vascular development contributing to the differentiation of mesenchymal stem cells into endothelial cells (144-146). 
Notably, it was demonstrated that nestin expression in tumour cells correlated with the area and the number of nestin ${ }^{+}$ vessels, which may support hypotheses on vascular mimicry and/or the trans-differentiation of CSCs into endothelial cells $(147,148)$. In BC, numerous studies have reported the presence of dysfunctional and disorganized vessels with a defective endothelium, in addition to the presence of vascularlike channels formed of tumour cells (149-151). Bussolati et al (87) demonstrated that nestin-expressing breast tumour CSCs were able to differentiate into epithelial cells and also into endothelial cells, in vitro and in vivo. Culturing nestin ${ }^{+}$ CSCs in the presence of serum promoted their differentiation towards the epithelial lineage. On the other hand, culturing nestin ${ }^{+}$CSCs in the presence of VEGF resulted in their differentiation into endothelial cells. Differentiated endothelial cells were able to express endothelial markers and organize into capillary-like structures in Matrigel. Furthermore, implantation of nestin ${ }^{+}$CSCs in severe combined immunodeficient (SCID) mice led to tumour development in which some of the intratumoural vessels were of human origin, suggesting the in vivo endothelial differentiation of CSCs. Notably, the study also demonstrated that endothelial-differentiated cells derived from nestin ${ }^{+}$CSCs were able to form an in vivo human vessel network and eventually an epithelial tumour when implanted in Matrigel in SCID mice. This may suggest that a non-differentiated population of tumorigenic nestin ${ }^{+} \mathrm{CSCs}$ is maintained among endothelial-differentiated breast CSCs (87).

\section{Nestin in BC-targeted therapy}

Undoubtedly, nestin is a valuable predictive marker which has the potential to be implemented in clinical practice, in order to achieve improved and more accurate diagnosis of BC. Since the use of nestin-targeted treatment in the mouse model of BC-related brain metastasis has resulted in a notable inhibition of disease progression, further research on possible applications in clinical patients is worthy of attention (110). A number of studies on different types of neoplasms have confirmed that inhibition of nestin results in the decreased proliferation, migration and invasion of tumour cells $(61,88,152-154)$. Notably, nestin expression is primarily restricted to a few types of normal cells, while it is abundantly expressed by tumour cells, newly-formed vessels and CSCs. Therefore, the therapy targeting nestin may be a potent and multidirectional therapeutic strategy with limited side effects. Improved understanding of the mechanisms through which nestin facilitates $\mathrm{BC}$ may aid the development of a powerful novel therapeutic agent.

\section{Conclusion}

The emerging evidence suggests that nestin is undeniably an important factor involved in $\mathrm{BC}$ progression (Fig. 1A). In the breast, nestin expression is detected in the basal/myoepithelial layer of normal mammary glands (Fig. 1B) in basal-like BC (Fig. 1C) and BC-associated vessels (Fig. 1D). As a specific marker of basal-like tumours and a marker of poor prognosis, it has the potential to become a biomarker used in daily clinical practice. Numerous studies have confirmed the role of nestin in important processes in tumour progression, including self-renewal and angiogenesis; however, the molecular mechanisms underlying these phenomena require further clarification. In conclusion, in BC, nestin may serve as a promising prognostic factor and a potential therapeutic target for tumour suppression and angiogenesis inhibition.

\section{Acknowledgements}

Not applicable.

\section{Funding}

The present study was supported by Wroclaw Medical University (grant no. Pbmn 192).

\section{Availability of data and materials}

Not applicable.

\section{Authors' contributions}

AN made substantial contributions to the conception of the article and created the major draft of the manuscript; PD contributed to the conception of the article and revised the manuscript critically for important intellectual content.

\section{Ethics approval and consent to participate}

Not applicable.

\section{Consent for publication}

Not applicable.

\section{Competing interests}

The authors declare that they have no competing interests.

\section{References}

1. Torre LA, Bray F, Siegel RL, Ferlay J, Lortet-Tieulent J and Jemal A: Global cancer statistics, 2012. CA Cancer J Clin 65: 87-108, 2015.

2. Bray F, McCarron P and Parkin DM: The changing global patterns of female breast cancer incidence and mortality. Breast Cancer Res 6: 229-239, 2004.

3. DeSantis CE, Bray F, Ferlay J, Lortet-Tieulent J, Anderson BO and Jemal A: International variation in female breast cancer incidence and mortality rates. Cancer Epidemiol Biomarkers Prev 24: 1495-1506, 2015

4. Ekwueme DU, Guy GP Jr, Rim SH, White A, Hall IJ, Fairley TL and Dean HD: Health and economic impact of breast cancer mortality in young women, 1970-2008. Am J Prev Med 46: 71-79, 2014

5. Dai X, Xiang L, Li T and Bai Z: Cancer Hallmarks, Biomarkers and breast cancer molecular subtypes. J Cancer 7: 1281-1294, 2016.

6. Zardavas D, Irrthum A, Swanton C and Piccart M: Clinical management of breast cancer heterogeneity. Nat Rev Clin Oncol 12: 381-394, 2015.

7. Koren S and Bentires-Alj M: Breast tumor heterogeneity: Source of fitness, Hurdle for Therapy. Mol Cell 60: 537-546, 2015.

8. Lacroix M, Toillon RA and Leclercq G: Stable 'portrait' of breast tumors during progression: Data from biology, pathology and genetics. Endocr Relat Cancer 11: 497-522, 2004.

9. Simpson PT, Reis-Filho JS, Gale T and Lakhani SR: Molecular evolution of breast cancer. J Pathol 205: 248-254, 2005. 
10. Perou CM, Sørlie T, Eisen MB, van de Rijn M, Jeffrey SS, Rees CA, Pollack JR, Ross DT, Johnsen H, Akslen LA, et al: Molecular portraits of human breast tumours. Nature 406 747-752, 2000

11. Sørlie T, Perou CM, Tibshirani R, Aas T, Geisler S, Johnsen H, Hastie T, Eisen MB, van de Rijn M, Jeffrey SS, et al: Gene expression patterns of breast carcinomas distinguish tumor subclasses with clinical implications. Proc Natl Acad Sci USA 98: 10869-10874, 2001.

12. Sorlie T, Tibshirani R, Parker J, Hastie T, Marron JS, Nobel A, Deng S, Johnsen H, Pesich R, Geisler S, et al: Repeated observation of breast tumor subtypes in independent gene expression data sets. Proc Natl Acad Sci USA 100: 8418-8423, 2003.

13. Turner NC and Reis-Filho JS: Basal-like breast cancer and the BRCA1 phenotype. Oncogene 25: 5846-5853, 2006.

14. Fang Y, Zhang Q, Wang X, Yang X, Wang X, Huang Z, Jiao Y and Wang J: Quantitative phosphoproteomics reveals genistein as a modulator of cell cycle and DNA damage response pathways in triple-negative breast cancer cells. Int J Oncol 48: 1016-1028, 2016

15. Gnant M, Harbeck N and Thomssen C: St. Gallen 2011: Summary of the Consensus Discussion. Breast Care (Basel) 6 136-141, 2011.

16. Raman V, Fuentes Lorenzo JL, Stashenko EE, Levy M, Levy MM and Camarillo IG: Lippia origanoides extract induces cell cycle arrest and apoptosis and suppresses NF- $\mathrm{B}$ signaling in triple-negative breast cancer cells. Int J Oncol 51: 1801-1808, 2017.

17. Lee A and Djamgoz MBA: Triple negative breast cancer: Emerging therapeutic modalities and novel combination therapies. Cancer Treat Rev 62: 110-122, 2018.

18. Yao H, He G, Yan S, Chen C, Song L, Rosol TJ and Deng X Triple-negative breast cancer: Is there a treatment on the horizon? Oncotarget 8: 1913-1924, 2017.

19. Prat A, Pineda E, Adamo B, Galván P, Fernández A, Gaba L, Díez M, Viladot M, Arance A and Muñoz M: Clinical implications of the intrinsic molecular subtypes of breast cancer. Breast 24 (Suppl 2): S26-S35, 2015.

20. Fulford LG, Easton DF, Reis-Filho JS, Sofronis A, Gillett CE, Lakhani SR and Hanby A: Specific morphological features predictive for the basal phenotype in grade 3 invasive ductal carcinoma of breast. Histopathology 49: 22-34, 2006.

21. Gudjonsson T, Adriance MC, Sternlicht MD, Petersen OW and Bissell MJ: Myoepithelial cells: Their origin and function in breast morphogenesis and neoplasia. J Mammary Gland Biol Neoplasia 10: 261-272, 2005

22. Badowska-Kozakiewicz AM and Budzik MP: Immunohistochemical characteristics of basal-like breast cancer. Contemp Oncol (Pozn) 20: 436-443, 2016.

23. Nielsen TO, Hsu FD, Jensen K, Cheang M, Karaca G, Hu Z Hernandez-Boussard T, Livasy C, Cowan D, Dressler L, et al: Immunohistochemical and clinical characterization of the basallike subtype of invasive breast carcinoma. Clin Cancer Res 10: 5367-5374, 2004

24. Cheang MC, Voduc D, Bajdik C, Leung S, McKinney S, Chia SK, Perou CM and Nielsen TO: Basal-like breast cancer defined by five biomarkers has superior prognostic value than triple-negative phenotype. Clin Cancer Res 14: 1368-1376, 2008.

25. Prat A, Adamo B, Cheang MC, Anders CK, Carey LA and Perou CM: Molecular characterization of basal-like and non-basal-like triple-negative breast cancer. Oncologist 18 : 123-133, 2013

26. Lachapelle $\mathrm{J}$ and Foulkes $\mathrm{W}$ : Triple-negative and basal-like breast cancer: Implications for oncologists. Curr Oncol 18 : 161-164, 2011.

27. Bertucci F, Finetti P, Viens P and Birnbaum D: Difference in therapeutic response between basal and nonbasal triple-negative breast cancers. Oncologist 18: 1060-1061, 2013.

28. Prat A and Perou CM: Deconstructing the molecular portraits of breast cancer. Mol Oncol 5: 5-23, 2011.

29. Sheffield BS, Kos Z, Asleh-Aburaya K, Wang XQ, Leung S, Gao D, Won J, Chow C, Rachamadugu R, Stijleman I, et al: Molecular subtype profiling of invasive breast cancers weakly positive for estrogen receptor. Breast Cancer Res Treat 155: 483-490, 2016

30. Prabhu JS, Korlimarla A, Desai K, Alexander A, Raghavan R, Anupama C, Dendukuri N, Manjunath S, Correa M, Raman N, et al: A majority of low (1-10\%) ER positive breast cancers behave like hormone receptor negative tumors. J Cancer 5: $156-165,2014$
31. Iwamoto T, Booser D, Valero V, Murray JL, Koenig K, Esteva FJ, Ueno NT, Zhang J, Shi W, Qi Y, et al: Estrogen receptor (ER) mRNA and ER-related gene expression in breast cancers that are $1 \%$ to $10 \%$ ER-positive by immunohistochemistry. J Clin Oncol 30: 729-734, 2012

32. Nadji M, Gomez-Fernandez C, Ganjei-Azar P and Morales AR: Immunohistochemistry of estrogen and progesterone receptors reconsidered: Experience with 5,993 breast cancers. Am J Clin Pathol 123: 21-27, 2005

33. Khoshnoud MR, Löfdahl B, Fohlin H, Fornander T, Stål O, Skoog L, Bergh J and Nordenskjöld B: Immunohistochemistry compared to cytosol assays for determination of estrogen receptor and prediction of the long-term effect of adjuvant tamoxifen. Breast Cancer Res Treat 126: 421-430, 2011.

34. Asleh K, Won JR, Gao D, Voduc KD and Nielsen TO: Nestin expression in breast cancer: Association with prognosis and subtype on 3641 cases with long-term follow-up. Breast Cancer Res Treat 168: 107-115, 2018.

35. Asleh-Aburaya K, Sheffield BS, Kos Z, Won JR, Wang XQ, Gao D, Wolber R, Gilks CB, Bernard PS, Chia SK, et al: Basal biomarkers nestin and INPP4b identify intrinsic subtypes accurately in breast cancers that are weakly positive for oestrogen receptor. Histopathology 70: 185-194, 2017.

36. Michalczyk K and Ziman M: Nestin structure and predicted function in cellular cytoskeletal organisation. Histol Histopathol 20: 665-671,2005

37. Wiese C, Rolletschek A, Kania G, Blyszczuk P, Tarasov KV, Tarasova Y, Wersto RP, Boheler KR and Wobus AM: Nestin expression - a property of multi-lineage progenitor cells? Cell Mol Life Sci 61: 2510-2522, 2004.

38. Mokrý J and Němecek S: Immunohistochemical detection of intermediate filament nestin. Acta Medica (Hradec Kralove) 41: 73-80, 1998

39. Cattaneo E and McKay R: Proliferation and differentiation of neuronal stem cells regulated by nerve growth factor. Nature 347: $762-765,1990$

40. Lendahl U, Zimmerman LB and McKay RD: CNS stem cells express a new class of intermediate filament protein. Cell 60: 585-595, 1990

41. Krum JM and Rosenstein JM: Transient coexpression of nestin, GFAP, and vascular endothelial growth factor in mature reactive astroglia following neural grafting or brain wounds. Exp Neurol 160: 348-360, 1999.

42. Vaittinen S, Lukka R, Sahlgren C,Hurme T, Rantanen J,Lendahl U, Eriksson JE and Kalimo H: The expression of intermediate filament protein nestin as related to vimentin and desmin in regenerating skeletal muscle. J Neuropathol Exp Neurol 60: 588-597, 2001.

43. Lindqvist J, Torvaldson E, Gullmets J, Karvonen H, Nagy A, Taimen P and Eriksson JE: Nestin contributes to skeletal muscle homeostasis and regeneration. J Cell Sci 130: 2833-2842, 2017.

44. About I, Laurent-Maquin D, Lendahl U and Mitsiadis TA: Nestin expression in embryonic and adult human teeth under normal and pathological conditions. Am J Pathol 157: 287-295, 2000.

45. Lin RC, Matesic DF, Marvin M, McKay RD and Brüstle O Re-expression of the intermediate filament nestin in reactive astrocytes. Neurobiol Dis 2: 79-85, 1995.

46. Sejersen $T$ and Lendahl U: Transient expression of the intermediate filament nestin during skeletal muscle development. J Cell Sci 106: 1291-1300, 1993.

47. Kachinsky AM, Dominov JA and Miller JB: Myogenesis and the intermediate filament protein, nestin. Dev Biol 165: 216-228, 1994.

48. Kachinsky AM, Dominov JA and Miller JB: Intermediate filaments in cardiac myogenesis: Nestin in the developing mouse heart. J Histochem Cytochem 43: 843-847, 1995.

49. Terling C, Rass A, Mitsiadis TA, Fried K, Lendahl U and Wroblewski J: Expression of the intermediate filament nestin during rodent tooth development. Int J Dev Biol 39: 947-956, 1995

50. Fröjdman K, Pelliniemi LJ, Lendahl U, Virtanen I and Eriksson JE: The intermediate filament protein nestin occurs transiently in differentiating testis of rat and mouse. Differentiation 61: 243-249, 1997

51. Zulewski H, Abraham EJ, Gerlach MJ, Daniel PB, Moritz W, Müller B, Vallejo M, Thomas MK and Habener JF: Multipotential nestin-positive stem cells isolated from adult pancreatic islets differentiate ex vivo into pancreatic endocrine, exocrine, and hepatic phenotypes. Diabetes 50: 521-533, 2001.

52. Vanderwinden JM, Gillard K, De Laet MH, Messam CA and Schiffmann SN: Distribution of the intermediate filament nestin in the muscularis propria of the human gastrointestinal tract. Cell Tissue Res 309: 261-268, 2002 
53. Vogel W, Grünebach F, Messam CA, Kanz L, Brugger W and Bühring HJ: Heterogeneity among human bone marrowderived mesenchymal stem cells and neural progenitor cells. Haematologica 88: 126-133, 2003.

54. Amoh Y, Yang M, Li L, Reynoso J, Bouvet M, Moossa AR, Katsuoka K and Hoffman RM: Nestin-linked green fluorescent protein transgenic nude mouse for imaging human tumor angiogenesis. Cancer Res 65: 5352-5357, 2005.

55. Mokrý J, Cízková D, Filip S, Ehrmann J, Osterreicher J, Kolár Z and English D: Nestin expression by newly formed human blood vessels. Stem Cells Dev 13: 658-664, 2004.

56. Nowak A, Grzegrzolka J, Paprocka M, Piotrowska A, Rys J, Matkowski R and Dziegiel P: Nestin-positive microvessel density is an independent prognostic factor in breast cancer. Int J Oncol 51: 668-676, 2017.

57. Tohyama T, Lee VM, Rorke LB, Marvin M, McKay RD and Trojanowski JQ: Nestin expression in embryonic human neuroepithelium and in human neuroepithelial tumor cells. Lab Invest 66: 303-313, 1992.

58. Dahlstrand J, Collins VP and Lendahl U: Expression of the class VI intermediate filament nestin in human central nervous system tumors. Cancer Res 52: 5334-5341, 1992.

59. Li H, Cherukuri P, Li N, Cowling V, Spinella M, Cole M, Godwin AK, Wells W and DiRenzo J: Nestin is expressed in the basal/myoepithelial layer of the mammary gland and is a selective marker of basal epithelial breast tumors. Cancer Res 67: 501-510, 2007

60. Kleeberger W, Bova GS, Nielsen ME, Herawi M, Chuang AY, Epstein JI and Berman DM: Roles for the stem cell associated intermediate filament Nestin in prostate cancer migration and metastasis. Cancer Res 67: 9199-9206, 2007.

61. Matsuda Y, Naito Z, Kawahara K, Nakazawa N, Korc M and Ishiwata T: Nestin is a novel target for suppressing pancreatic cancer cell migration, invasion and metastasis. Cancer Biol Ther 11: 512-523, 2011

62. Sterlacci W, Savic S, Fiegl M, Obermann E and Tzankov A Putative stem cell markers in non-small-cell lung cancer: A clinicopathologic characterization. J Thorac Oncol 9: 41-49, 2014

63. Qin Q, Sun Y, Fei M, Zhang J, Jia Y, Gu M, Xia R, Chen S and Deng A: Expression of putative stem marker nestin and CD133 in advanced serous ovarian cancer. Neoplasma 59: 310-315, 2012.

64. Ishiwata T, Matsuda $\mathrm{Y}$ and Naito Z: Nestin in gastrointestinal and other cancers: Effects on cells and tumor angiogenesis. World J Gastroenterol 17: 409-418, 2011.

65. Piras F, Perra MT, Murtas D, Minerba L, Floris C, Maxia C, Demurtas P, Ugalde J, Ribatti D and Sirigu P: The stem cell marker nestin predicts poor prognosis in human melanoma. Oncol Rep 23: 17-24, 2010

66. Zhong B, Wang T, Lun X, Zhang J, Zheng S, Yang W, Li W, Xiang AP and Chen Z: Contribution of nestin positive esophageal squamous cancer cells on malignant proliferation, apoptosis, and poor prognosis. Cancer Cell Int 14: 57, 2014.

67. Li S, Lai Y, Fan J, Shen C and Che G: Clinicopathological and prognostic significance of Nestin expression in patients with non-small cell lung cancer: A systematic review and metaanalysis. Clin Exp Med 17: 161-174, 2017.

68. Neradil J and Veselska R: Nestin as a marker of cancer stem cells. Cancer Sci 106: 803-811, 2015.

69. Guérette D, Khan PA, Savard PE and Vincent M: Molecular evolution of type VI intermediate filament proteins. BMC Evol Biol 7: 164, 2007.

70. Chou YH, Khuon S, Herrmann H and Goldman RD: Nestin promotes the phosphorylation-dependent disassembly of vimentin intermediate filaments during mitosis. Mol Biol Cell 14: 1468-1478, 2003

71. Sjöberg G, Jiang WQ, Ringertz NR, Lendahl U and Sejersen T: Colocalization of nestin and vimentin/desmin in skeletal muscle cells demonstrated by three-dimensional fluorescence digital imaging microscopy. Exp Cell Res 214: 447-458, 1994.

72. Holle AW, Kalafat M, Ramos AS, Seufferlein T, Kemkemer R and Spatz JP: Intermediate filament reorganization dynamically influences cancer cell alignment and migration. Sci Rep 7: 45152, 2017.

73. Makihara $\mathrm{H}$, Inaba $\mathrm{H}$, Enomoto $\mathrm{A}$, Tanaka $\mathrm{H}$, Tomono $\mathrm{Y}$, Ushida K, Goto M, Kurita K, Nishida Y, Kasahara K, et al: Desmin phosphorylation by Cdk 1 is required for efficient separation of desmin intermediate filaments in mitosis and detected in murine embryonic/newborn muscle and human rhabdomyosarcoma tissues. Biochem Biophys Res Commun 478: 1323-1329, 2016.
74. Sahlgren CM, Mikhailov A, Vaittinen S, Pallari HM, Kalimo H, Pant $\mathrm{HC}$ and Eriksson JE: Cdk5 regulates the organization of Nestin and its association with p35. Mol Cell Biol 23: 5090-5106, 2003.

75. Sahlgren CM, Mikhailov A, Hellman J, Chou YH, Lendahl U, Goldman RD and Eriksson JE: Mitotic reorganization of the intermediate filament protein nestin involves phosphorylation by cdc2 kinase. J Biol Chem 276: 16456-16463, 2001.

76. Matsuda Y, Ishiwata T, Yoshimura H, Yamahatsu K, Minamoto T and Arai T: Nestin phosphorylation at threonines 315 and 1299 correlates with proliferation and metastasis of human pancreatic cancer. Cancer Sci 108: 354-361, 2017.

77. Pozo K and Bibb JA: The Emerging Role of Cdk5 in Cancer. Trends Cancer 2: 606-618, 2016.

78. Chiker S, Pennaneach V, Loew D, Dingli F, Biard D, Cordelières FP, Gemble S, Vacher S, Bieche I, Hall J, et al: Cdk5 promotes DNA replication stress checkpoint activation through RPA-32 phosphorylation, and impacts on metastasis free survival in breast cancer patients. Cell Cycle 14: 3066-3078, 2015.

79. Liang Q, Li L, Zhang J, Lei Y, Wang L, Liu DX, Feng J, Hou P, Yao R, Zhang Y, et al: CDK5 is essential for TGF- $\beta 1$-induced epithelial-mesenchymal transition and breast cancer progression. Sci Rep 3: 2932, 2013

80. Sahlgren CM, Pallari HM, He T, Chou YH, Goldman RD and Eriksson JE: A nestin scaffold links Cdk5/p35 signaling to oxidant-induced cell death. EMBO J 25: 4808-4819, 2006.

81. Choi SS, Syn WK, Karaca GF, Omenetti A, Moylan CA, Witek RP, Agboola KM, Jung Y, Michelotti GA and Diehl AM: Leptin promotes the myofibroblastic phenotype in hepatic stellate cells by activating the hedgehog pathway. J Biol Chem 285: 36551-36560, 2010

82. Habib JG and O'Shaughnessy JA: The hedgehog pathway in triple-negative breast cancer. Cancer Med 5: 2989-3006, 2016.

83. Fan Y, Chong YS, Choolani MA, Cregan MD and Chan JK: Unravelling the mystery of stem/progenitor cells in human breast milk. PLoS One 5: e14421, 2010.

84. Patki S, Kadam S, Chandra V and Bhonde R: Human breast milk is a rich source of multipotent mesenchymal stem cells. Hum Cell 23: 35-40, 2010.

85. Cregan MD, Fan Y, Appelbee A, Brown ML, Klopcic B, Koppen J, Mitoulas LR, Piper KM, Choolani MA, Chong YS, et al: Identification of nestin-positive putative mammary stem cells in human breastmilk. Cell Tissue Res 329: 129-136, 2007.

86. Hosseini SM, Talaei-Khozani T, Sani M and Owrangi B Differentiation of human breast-milk stem cells to neural stem cells and neurons. Neurol Res Int 2014: 807896, 2014.

87. Bussolati B, Grange C, Sapino A and Camussi G: Endothelial cell differentiation of human breast tumour stem/progenitor cells. J Cell Mol Med 13: 309-319, 2009.

88. Zhao Z, Lu P, Zhang H, Xu H, Gao N, Li M and Liu C: Nestin positively regulates the $\mathrm{Wnt} / \beta$-catenin pathway and the proliferation, survival and invasiveness of breast cancer stem cells. Breast Cancer Res 16: 408, 2014.

89. Apostolou P, Toloudi M, Chatziioannou M, Ioannou E and Papasotiriou I: Cancer stem cells stemness transcription factors expression correlates with breast cancer disease stage. Curr Stem Cell Res Ther 7: 415-419, 2012.

90. Parry S, Savage K, Marchiò C and Reis-Filho JS: Nestin is expressed in basal-like and triple negative breast cancers. J Clin Pathol 61: 1045-1050,2008

91. Liu C, Chen B, Zhu J, Zhang R, Yao F, Jin F, Xu H and Lu P. Clinical implications for nestin protein expression in breast cancer. Cancer Sci 101: 815-819, 2010.

92. Piras F, Ionta MT, Lai S, Perra MT, Atzori F, Minerba L, Pusceddu V, Maxia C, Murtas D, Demurtas P, et al: Nestin expression associates with poor prognosis and triple negative phenotype in locally advanced (T4) breast cancer. Eur J Histochem 55: e39, 2011.

93. Won JR, Gao D, Chow C, Cheng J, Lau SY, Ellis MJ, Perou CM, Bernard PS and Nielsen TO: A survey of immunohistochemical biomarkers for basal-like breast cancer against a gene expression profile gold standard. Mod Pathol 26: 1438-1450, 2013.

94. Tampaki EC, Tampakis A, Nonni A, Kontzoglou K, Patsouris E and Kouraklis G: Nestin and cluster of differentiation 146 expression in breast cancer: Predicting early recurrence by targeting metastasis? Tumour Biol 39: 1010428317691181, 2017.

95. Gao N, Xu H, Liu C, Xu H, Chen G, Wang X, Li Y and Wang Y: Nestin: Predicting specific survival factors for breast cancer. Tumour Biol 35: 1751-1755, 2014 
96. Krüger K, Wik E, Knutsvik G, Nalwoga H, Klingen TA Arnes JB, Chen Y, Mannelqvist M, Dimitrakopoulou K, Stefansson IM, et al: Expression of Nestin associates with BRCA1 mutations, a basal-like phenotype and aggressive breast cancer. Sci Rep 7: 1089, 2017.

97. Nowak A, Grzegrzółka J, Kmiecik A, Piotrowska A Matkowski R and Dzięgiel P: Role of nestin expression in angiogenesis and breast cancer progression. Int J Oncol 52: 527-535, 2018

98. Huang A, Cao S and Tang L: The tumor microenvironment and inflammatory breast cancer. J Cancer 8: 1884-1891, 2017.

99. van Uden DJ, van Laarhoven HW, Westenberg AH, de Wilt JH and Blanken-Peeters CF: Inflammatory breast cancer: An overview. Crit Rev Oncol Hematol 93: 116-126, 2015.

100.Xiao Y, Ye Y, Yearsley K, Jones S and Barsky SH: The lymphovascular embolus of inflammatory breast cancer expresses a stem cell-like phenotype. Am J Pathol 173: 561-574, 2008.

101. Rögelsperger O, Ekmekcioglu C, Jäger W, Klimpfinger M, Königsberg R, Krenbek D, Sellner F and Thalhammer T: Coexpression of the melatonin receptor 1 and nestin in human breast cancer specimens. J Pineal Res 46: 422-432, 2009.

102.Laakso M, Loman N, Borg A and Isola J: Cytokeratin 5/14positive breast cancer: True basal phenotype confined to BRCA1 tumors. Mod Pathol 18: 1321-1328, 2005.

103. Badve S, Dabbs DJ, Schnitt SJ, Baehner FL, Decker T, Eusebi V, Fox SB, Ichihara S, Jacquemier J, Lakhani SR, et al: Basal-like and triple-negative breast cancers: A critical review with an emphasis on the implications for pathologists and oncologists. Mod Pathol 24: 157-167, 2011

104. Foulkes WD, Metcalfe K, Hanna W, Lynch HT, Ghadirian P, Tung N, Olopade O, Weber B, McLennan J, Olivotto IA, et al: Disruption of the expected positive correlation between breast tumor size and lymph node status in BRCA1-related breast carcinoma. Cancer 98: 1569-1577, 2003.

105. Lehmann BD, Bauer JA, Chen X, Sanders ME, Chakravarthy AB Shyr Y and Pietenpol JA: Identification of human triple-negative breast cancer subtypes and preclinical models for selection of targeted therapies. J Clin Invest 121: 2750-2767, 2011.

106.Zimmer AS, Gillard M, Lipkowitz S and Lee JM: Update on PARP inhibitors in breast cancer. Curr Treat Options Oncol 19: 21, 2018.

107. Sihto H, Lundin J, Lundin M, Lehtimäki T, Ristimäki A, Holli K, Sailas L, Kataja V, Turpeenniemi-Hujanen T, Isola J, et al: Breast cancer biological subtypes and protein expression predict for the preferential distant metastasis sites: A nationwide cohort study. Breast Cancer Res 13: R87, 2011.

108. de Groot AE, Roy S, Brown JS, Pienta KJ and Amend SR: Revisiting Seed and Soil: Examining the primary tumor and cancer cell foraging in metastasis. Mol Cancer Res 15: 361-370, 2017.

109. Custódio-Santos T, Videira M and Brito MA: Brain metastasization of breast cancer. Biochim Biophys Acta 1868: 132-147, 2017.

110. Meisen WH, Dubin S, Sizemore ST, Mathsyaraja H, Thies K, Lehman NL, Boyer P, Jaime-Ramirez AC, Elder JB, Powell K, et al: Changes in BAI1 and nestin expression are prognostic indicators for survival and metastases in breast cancer and provide opportunities for dual targeted therapies. Mol Cancer Ther 14: 307-314, 2015

111. Neve RM, Chin K, Fridlyand J, Yeh J, Baehner FL, Fevr T, Clark L, Bayani N, Coppe JP, Tong F, et al: A collection of breast cancer cell lines for the study of functionally distinct cancer subtypes. Cancer Cell 10: 515-527, 2006.

112. Sin WC and Lim CL: Breast cancer stem cells-from origins to targeted therapy. Stem Cell Investig 4: 96, 2017.

113. Albini A, Bruno A, Gallo C, Pajardi G, Noonan DM and Dallaglio K: Cancer stem cells and the tumor microenvironment: Interplay in tumor heterogeneity. Connect Tissue Res 56: 414-425, 2015.

114. Shima H, Yamada A, Ishikawa T and Endo I: Are breast cancer stem cells the key to resolving clinical issues in breast cancer therapy? Gland Surg 6: 82-88, 2017.

115. Singh SK, Clarke ID, Terasaki M, Bonn VE, Hawkins C, Squire J and Dirks PB: Identification of a cancer stem cell in human brain tumors. Cancer Res 63: 5821-5828, 2003.

116. Singh SK, Clarke ID, Hide T and Dirks PB: Cancer stem cells in nervous system tumors. Oncogene 23: 7267-7273, 2004.

117. Al-Hajj M, Wicha MS, Benito-Hernandez A, Morrison SJ and Clarke MF: Prospective identification of tumorigenic breast cancer cells. Proc Natl Acad Sci USA 100: 3983-3988, 2003.
118. Wang H, Wang L, Song Y, Wang S, Huang X, Xuan Q, Kang X and Zhang Q: CD $44^{+} / \mathrm{CD} 24-$ phenotype predicts a poor prognosis in triple-negative breast cancer. Oncol Lett 14: 5890-5898, 2017.

119. Ma F, Li H, Wang H, Shi X, Fan Y, Ding X, Lin C, Zhan Q, Qian H and Xu B: Enriched CD44(+)/CD24(-) population drives the aggressive phenotypes presented in triple-negative breast cancer (TNBC). Cancer Lett 353: 153-159, 2014

120. Liu C, Cao X, Zhang Y, Xu H, Zhang R, Wu Y, Lu P and Jin F Co-expression of Oct-4 and Nestin in human breast cancers. Mol Biol Rep 39: 5875-5881, 2012.

121. Xiao Y, Ye Y, Zou X, Jones S, Yearsley K, Shetuni B, Tellez J and Barsky SH: The lymphovascular embolus of inflammatory breast cancer exhibits a Notch 3 addiction. Oncogene 30 : 287-300, 2011.

122. Chang R, Zhang P and You J: Post-translational modifications of EMT transcriptional factors in cancer metastasis. Open Life Sci 11: 237-243, 2016

123. Grzegrzolka J, Biala M, Wojtyra P, Kobierzycki C, Olbromski M, Gomulkiewicz A, Piotrowska A, Rys J, Podhorska-Okolow M and Dziegiel P: Expression of EMT markers SLUG and TWIST in breast cancer. Anticancer Res 35: 3961-3968, 2015.

124. Liang Q, Li W, Zhao Z and Fu Q: Advancement of Wnt signal pathway and the target of breast cancer. Open Life Sci 11: 98-104, 2016.

125. Luo G, Huang D, Tao R and Chen J: The role of E-cadherin - 160C/A polymorphism in breast cancer. Open Life Sci 11: $110-115,2016$

126. Odiba A, Ottah V, Anunobi O, Edeke AA, Ukegbu CY, Chukwunonyelum I, Onosakponome I and Joshua PE: Research progress in oncology. Highlighting and exploiting the roles of several strategic proteins in understanding cancer biology. Open Life Sci 11: 331-347, 2016.

127. de Sousa E Melo F and Vermeulen L: Wnt Signaling in cancer stem cell biology. Cancers (Basel) 8: 8, 2016.

128. Sun M, Zhang N, Wang X, Li Y, Qi W, Zhang H, Li Z and Yang Q: Hedgehog pathway is involved in nitidine chloride induced inhibition of epithelial-mesenchymal transition and cancer stem cells-like properties in breast cancer cells. Cell Biosci 6: 44, 2016

129. Wang X, Zhang N, Huo Q, Sun M, Dong L, Zhang Y, Xu G and Yang Q: Huaier aqueous extract inhibits stem-like characteristics of MCF7 breast cancer cells via inactivation of hedgehog pathway. Tumour Biol 35: 10805-10813, 2014.

130. Hatsell S and Frost AR: Hedgehog signaling in mammary gland development and breast cancer. J Mammary Gland Bio Neoplasia 12: 163-173, 2007.

131. Feng W, Liu S, Zhu R, Li B, Zhu Z, Yang J and Song C: SOX10 induced Nestin expression regulates cancer stem cell properties of TNBC cells. Biochem Biophys Res Commun 485: 522-528, 2017.

132. Dravis C, Spike BT, Harrell JC, Johns C, Trejo CL, Southard-Smith EM, Perou CM and Wahl GM: Sox 10 regulates stem/progenitor and mesenchymal cell states in mammary epithelial cells. Cell Reports 12: 2035-2048, 2015.

133. Carmeliet P and Jain RK: Angiogenesis in cancer and other diseases. Nature 407: 249-257, 2000.

134. Carmeliet P: Angiogenesis in life, disease and medicine. Nature 438: 932-936, 2005.

135. Folkman J: Tumor angiogenesis: Therapeutic implications. N Engl J Med 285: 1182-1186, 1971

136. Hanahan D and Folkman J: Patterns and emerging mechanisms of the angiogenic switch during tumorigenesis. Cell 86: 353-364, 1996.

137. Hanahan D and Weinberg RA: Hallmarks of cancer: The next generation. Cell 144: 646-674, 2011

138. Krupkova O Jr, Loja T, Zambo I and Veselska R: Nestin expression in human tumors and tumor cell lines. Neoplasma 57: 291-298, 2010

139. Krüger K, Stefansson IM, Collett K, Arnes JB, Aas T and Akslen LA: Microvessel proliferation by co-expression of endothelial nestin and $\mathrm{Ki}-67$ is associated with a basal-like phenotype and aggressive features in breast cancer. Breast 22: 282-288, 2013.

140. Paprocka M, Krawczenko A, Dus D, Kantor A, Carreau A, Grillon C and Kieda C: CD133 positive progenitor endothelial cell lines from human cord blood. Cytometry A 79: 594-602, 2011

141. Alliot F, Rutin J, Leenen PJ and Pessac B: Pericytes and periendothelial cells of brain parenchyma vessels co-express aminopeptidase $\mathrm{N}$, aminopeptidase $\mathrm{A}$, and nestin. J Neurosci Res 58: 367-378, 1999. 
142. Nakagawa S, Miki Y, Miyashita M, Hata S, Takahashi Y, Rai Y, Sagara Y, Ohi Y, Hirakawa H, Tamaki K, et al: Tumor microenvironment in invasive lobular carcinoma: Possible therapeutic targets. Breast Cancer Res Treat 155: 65-75, 2016.

143. Morikawa S, Baluk P, Kaidoh T, Haskell A, Jain RK and McDonald DM: Abnormalities in pericytes on blood vessels and endothelial sprouts in tumors. Am J Pathol 160: 985-1000, 2002.

144.Ikhapoh IA, Pelham CJ and Agrawal DK: Sry-type HMG box 18 contributes to the differentiation of bone marrow-derived mesenchymal stem cells to endothelial cells. Differentiation 89: 87-96, 2015.

145.Downes M and Koopman P: SOX18 and the transcriptional regulation of blood vessel development. Trends Cardiovasc Med 11: 318-324, 2001.

146. Pula B, Olbromski M, Wojnar A, Gomulkiewicz A, Witkiewicz W, Ugorski M, Dziegiel P and Podhorska-Okolow M: Impact of SOX18 expression in cancer cells and vessels on the outcome of invasive ductal breast carcinoma. Cell Oncol (Dordr) 36 469-483, 2013.

147.Liu TJ, Sun BC, Zhao XL, Zhao XM, Sun T, Gu Q, Yao Z, Dong XY, Zhao N and Liu N: $\mathrm{CD}_{133^{+}}$cells with cancer stem cell characteristics associates with vasculogenic mimicry in triple-negative breast cancer. Oncogene 32: 544-553, 2013.

148. Wang R, Chadalavada K, Wilshire J, Kowalik U, Hovinga KE, Geber A, Fligelman B, Leversha M, Brennan C and Tabar V: Glioblastoma stem-like cells give rise to tumour endothelium. Nature 468: 829-833, 2010.
149. Folberg R, Hendrix MJ and Maniotis AJ: Vasculogenic mimicry and tumor angiogenesis. Am J Pathol 156: 361-381, 2000.

150. Baluk P, Hashizume $\mathrm{H}$ and McDonald DM: Cellular abnormalities of blood vessels as targets in cancer. Curr Opin Genet Dev 15: 102-111, 2005

151. Shirakawa K, Kobayashi H, Heike Y, Kawamoto S, Brechbiel MW, Kasumi F, Iwanaga T, Konishi F, Terada M and Wakasugi $\mathrm{H}$ : Hemodynamics in vasculogenic mimicry and angiogenesis of inflammatory breast cancer xenograft. Cancer Res 62: 560-566, 2002.

152. Narita K, Matsuda Y, Seike M,Naito Z, Gemma A and Ishiwata T: Nestin regulates proliferation, migration, invasion and stemness of lung adenocarcinoma. Int J Oncol 44: 1118-1130, 2014

153. Akiyama M, Matsuda Y, Ishiwata T, Naito Z and Kawana S: Inhibition of the stem cell marker nestin reduces tumor growth and invasion of malignant melanoma. In: J Invest Dermatol 133: 1384-1387, 2013.

154. Matsuda Y, Ishiwata T, Yoshimura H, Yamashita S, Ushijima T and Arai T: Systemic administration of small interfering RNA targeting human nestin inhibits pancreatic cancer cell proliferation and metastasis. Pancreas 45: 93-100, 2016. 